\title{
Research
}

\section{Failures of metacognition and lack of insight in neuropsychiatric disorders}

\author{
Anthony S. David*, Nicholas Bedford, Ben Wiffen and James Gilleen \\ Section of Cognitive Neuropsychology, Department of Psychosis Studies, Institute of Psychiatry, \\ King's College London, De Crespigny Park, London, SE5 8AF, UK
}

Lack of insight or unawareness of illness are the hallmarks of many psychiatric disorders, especially schizophrenia (SCZ) and other psychoses and could be conceived of as a failure in metacognition. Research in this area in the mental health field $\mathrm{h}$ as burgeoned with the development and widespread use of standard assessment instruments and the mapping out of the clinical and neuropsychological correlates of insight and its loss. There has been a growing appreciation of the multi-faceted nature of the concept and of the different 'objects' of insight, such as the general awareness that one is ill, to more specific metacognitive awareness of individual symptoms, impairments and performance. This in turn has led to the notion that insight may show modularity and may fractionate across different domains and disorders, supported by work that directly compares metacognition of memory deficits and illness awareness in patients with SCZ, Alzheimer's disease and brain injury. The focus of this paper will be on the varieties of metacognitive failure in psychiatry, particularly the psychoses. We explore cognitive models based on self-reflectiveness and their possible social and neurological bases, including data from structural and functional MRI. The medial frontal cortex appears to play an important role in self-appraisal in health and disease.

Keywords: insight; awareness; schizophrenia; psychosis; self-reflectiveness; neuroimaging

Everyone complains of his lack of memory, but nobody of his want of judgment.

de Rochefoucauld (1613-1680)

\section{INTRODUCTION}

The topic of metacognition has had a huge stimulating effect on what might be termed cognitive neuropsychiatry-that is, the field that seeks to promote the study of cognitive processes underlying psychological and behavioural abnormalities. In particular, the sorts of abnormalities that have been illuminated when viewed in the light of metacognition include, most notably, autistic deficits (not considered here), but also psychotic symptoms. In a volume dedicated to metacognition and severe adult mental disorder, Saxe \& Offen [1] described two meanings for the term in this context. The first they called 'attributive metacognition', which concerns the ability to attribute beliefs and desires to oneself and was seen as a variety of self-knowledge. The second meaning they termed 'strategic metacognition', which denotes the ability to monitor and control ongoing mental activities. The definition continues:

Attributive and strategic metacognition differ from one another both in the objects of thoughts (beliefs and desires versus mental activities and plans) and actions

* Author for correspondence (anthony.david@kcl.ac.uk).

One contribution of 13 to a Theme Issue 'Metacognition: computation, neurobiology and function'. taken (attribution in the service of explanation versus monitoring in the service of control).

Saxe \& Offen [1, p. 14]

This paper concentrates on the strategic type of metacognition, but a certain blurring of the boundaries occurs when the outcome of the latter leads to a revision in the former. For example, monitoring of a cognitive operation may reveal deficits and impairments that then require a revision in self-knowledge, specifically the knowledge that one is impaired or ill or in need of help. Similarly, we may wish to expand the range of 'objects' under scrutiny to include not just mental operations and day-to-day beliefs and desires, but a particular set of beliefs about the self or personality that presumably change (if at all) at a slower pace.

The terminology used in clinical circles to capture these notions also requires some comment. In neuropsychiatry, the terms 'anosognosia' and 'lack of awareness' are often used synonymously to describe a collection of attitudes and behaviours directed at one's illness. Anosognosia may be used to convey lack of awareness of specific functions seen after brain injury, leading to, for example, hemiplegia [2]. In contrast, 'insight' (and occasionally, somewhat colloquially, 'denial' or 'being in denial') is typically used to describe the phenomenon in psychiatric disorders, such as schizophrenia (SCZ), addictions, bipolar disorder and even personality disorders, and in neurological conditions such as Alzheimer's disease (AD) and brain injury. Here, the expressed awareness in question refers to that of being ill in general, and, more specifically, the capacity to 


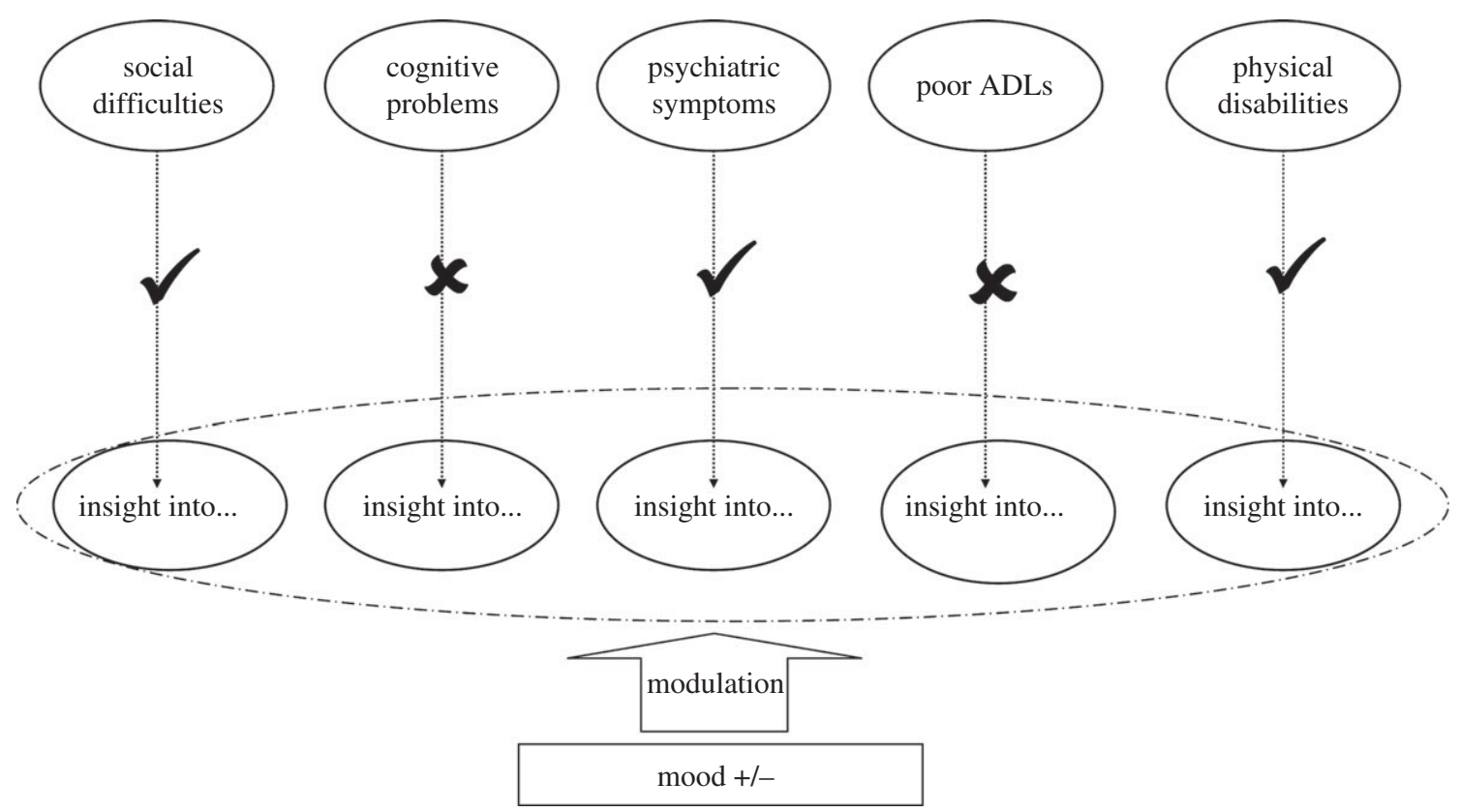

Figure 1. Illustrating a multiple modality-specific awareness systems (modularity) but with general modulation by factors such as mood. In this theoretical example, insight is preserved into 'objects' such as social difficulties, psychiatric symptoms and physical disability, but not cognitive problems and poor activities of daily living (ADLs). Adapted from [10].

judge impairment of, say, memory or social behaviour. It is also applied to judgements of the content of experiences or symptoms, such as delusions and hallucinations, as not being real [3,4]. Rather than lack of insight being a symptom in its own right, it is more usefully thought of as a relational concept: insight into something [5]. Broadly, this may encompass stated awareness of an objective, obvious (physical) deficit such as hemiplegia, or behaviour such as excessive alcohol intake, through to objects that are verifiable but invisible. One may or may not have insight into a mental failure or deficittrue metacognition-such as amnesia. This is different again from 'objects' that are purely subjective experiences, such as hallucinations, where the insight concerned may take the form: did I just hear the voice of my dead mother or was my mind playing tricks on me?

Insight research, particularly in relation to SCZ and the psychoses, has burgeoned over the past 20 years with the development of operationalized definitions and easy-to-administer rating scales. It was probably the realization that insight was not a unitary phenomenon, but rather a multi-dimensional construct, that revived interest in the field. This may have been because such a formulation rang true with clinicians. Furthermore, the separation of awareness of deficits or symptoms from their attribution chimed with advances in other areas of cognitive and behavioural science, such as social psychology (attribution theory) and developmental psychology ('theory of mind').

Lack of insight was once held to be the sine qua non of 'psychosis' [3], but this has given way to a more nuanced and quantitative view. David [3,4] proposed three insight dimensions: recognition of having a mental illness, compliance with treatment and the ability to label unusual mental events (e.g. hallucinations) as pathological. Amador et al. [6] split insight into five components: four relate to (un)awareness of having a mental disorder, of the effects of medication, of consequences of illness and of specific symptoms, and the final component is the attribution of symptoms to illness. Popular measures of insight include the Schedule for the Assessment of Insight-Expanded version (SAI-E) $[7,8]$ and the semi-structured interview: Scale to Assess Unawareness of Mental Disorder (SUMD) [6]. Many authors, particularly in the dementia and brain injury fields, have made use of patient-carer discrepancy questionnaires $[2,9,10]$ (see below).

Dividing insight into sub-components separates one aspect, namely detecting and labelling unusual mental events as pathological (as per schemes advanced by David and Amador and colleagues), which is metacognitive in the strategic sense defined above. Indeed, within schizophrenic psychopathology, the types of events or objects of contemplation extend to delusions, negative symptoms and thought disorder at the very least, and it appears that insight into one aspect does not necessarily predict insight into another (figure $1 ;$ [11]).

In this paper, we will summarize work specifically addressing the fractionation of insight in different disorders across domains of cognitive functions. Next, we will highlight some of the challenges in extending studies of metacognition from 'cold' information processing to 'hotter' areas of self-concept and the presentation of self and some preliminary findings. We will then describe some of the key findings on insight-related metacognition in psychiatric and neuropsychiatric disorders, including neuroimaging research.

\section{METACOGNITION ACROSS DIAGNOSTIC GROUPS}

Most clinical studies of metacognition consider a singlepatient population, but there is a case for comparing different patient groups on the same measures. Just as patients with SCZ have, in addition to their core symptoms, cognitive impairments and behavioural and social deficits, so patients with $\mathrm{AD}$ and brain injury may have a range of psychopathologies that they may 
Table 1. Demographic and insight data on clinical groups. NART, national adult reading test (estimate of premorbid IQ); SAI-E, Schedule for the Assessment of Insight-Expanded; SUMD, scale to assess unawareness of mental disorder; DEX, dysexecutive questionnaire.

\begin{tabular}{lccr}
\hline variable, mean (s.d.) & schizophrenia $(n=31)$ & brain injury $(n=26)$ & Alzheimer's $(n=27)$ \\
\hline age, years & $38.3(10.4)$ & $40.0(12.1)$ & $82.4(4.3)$ \\
sex, m/f & $16 / 15$ & $22 / 4$ & $14 / 13$ \\
premorbid IQ (NART) & $102.3(12.8)$ & $102.2(13.8)$ & $109.1(12.8)$ \\
SAI-E & $11.2(7.15)$ & $15.4(5.7)$ & $7.0(6.4)$ \\
SUMD awareness of mental illness & $3.37(1.6)$ & $1.92(1.43)$ & $4.04(1.4)$ \\
DEX discrepancy scores ${ }^{\text {a }}$ (mean and range) & $2.48(-33-31)$ & $-14.76(-55-15)$ & $-25.96(-62-13)$
\end{tabular}

${ }^{a}$ Self rating of difficulties minus informant rating of difficulties yielding a negative score. The more negative, the greater the discrepancy (greater patient unawareness).

or may not be able to monitor and appraise and of which they have varying degrees of awareness. We can ask whether the same factors associated with metacognition are consistent across the groups [12-14]. Modularity of 'awarenesses' is perhaps the most likely pattern from the neurological literature [15]. This is illustrated in figure 1 . In a large pan-European brain injury study [16], considerable within-diagnosis heterogeneity of awareness was found. Similarly, in the dementia field, different levels of awareness have been noted by contrasting behaviour with cognition [17-19].

We recently compared aspects of insight and metacognition in three different neuropsychiatric populations: SCZ, brain injury (BI) and probable AD $[9,10,20]$ (table 1). The former were mostly sub-acute, chronic and treated out-patients, plus some inpatients at the Maudsley Hospital, London, while the Alzheimer's group were locally dwelling subjects identified as part of a larger cohort study. The brain injury patients were a heterogeneous group with a mixture of traumatic, hypoxic and vascular aetiologies and with behavioural problems. Naturally, the patients were not matched on factors such as age and length of illness.

The groups were compared on measures of estimated premorbid IQ (National Adult Reading Test, NART) and clinician-rated and patient-carer-rated awareness scales. All were rated on the SAI-E, the SUMD and the Dysexecutive (DEX) Questionnaire (table 1).

The DEX Questionnaire from the Behavioural Assessment of the Dysexecutive Syndrome (BADS) [21] is a 20-item measure of functioning that addresses problems such as impulsivity, apathy, distractibility, unconcern for social rules and difficulties with abstract thinking. Informants rate patients' functioning and the patient rates him/herself on the scales, and the difference between patient and informant scores creates a discrepancy score. The greater and more negative the discrepancy between the scores, the greater the unawareness of the patient. Items are scored on a 5-point scale from 0 -(never) to 4-(very often). Hence, DEX discrepancy scores can range from -80 to +80 . So if a patient is rated by a carer as 'very often $=4$ ' on the behaviour 'losing his temper at the slightest thing', while the patient himself says that this occurs 'occasionally $=1$ ', then there is a discrepancy of -3 on that one item. A score of zero indicates perfect awareness in that the patient agrees with the level of impairment scored by their respective informant.

The validity of the discrepancy index in measuring insight and awareness or metacognitive failure may be questioned since it assumes that the informant is always correct (or 'gold standard'; see $[17,18]$ ). Nevertheless, the methodology has been found to be valuable and consistently shows underestimation of deficits by patients in relation to their informal caregivers.

Across the groups, patient- and informant-ratings of behavioural problems, as measured by the total DEX score, were highly discrepant in the $\mathrm{BI}$ and $\mathrm{AD}$ disease groups (table 1), representing low awareness of behavioural impairments, but this was much less so in the SCZ group, which suggests that patients in these different groups exhibit dissimilar levels of unawareness of behavioural deficits. This is despite the fact that the SCZ patients as a group were rated by clinicians on the SAI-E as having rather modest insight into their psychiatric disorder and symptoms $(15.4 \pm 5.7$ out of 28$)$, although not as poor as the BI group (11.2 \pm 7.15$)$, some of whom entirely denied that they had any impairments or deficits. Pooling all patients, DEX-discrepancy and SAI-E scores correlated moderately and significantly at $r=0.32 ; r=0.46$ in the BI group alone, but $r<0.2$ (ns) in the SCZ and AD groups. In other words, not only do patients with different neuropsychiatric disorders show very different levels of awareness into their dysexecutive problems, but there is also little relationship between a patient's ability to view their dysexecutive behaviours as problematic and their overall insight according to a clinician rating, perhaps because they are governed by different processes.

\section{META-MEMORY}

Metacognitive awareness can also be calculated as a discrepancy score between actual performance and ratings by the patient or other persons. Clare et al. [22] have developed the memory awareness rating scale (MARS), which provides a variety of awareness of memory measures based on discrepancy scores between predicted and actual functioning on the Rivermead behavioural memory test (RBMT; [23]) and pre-test, post-test self-ratings and informant ratings. Importantly, the MARS offers an 'isomorphic' and ecologically valid measure of awareness in as far as the questions are easily understood in terms of everyday memory tasks, and the questions that form the ratings are analogous to the RBMT sub-tests, thus allowing direct comparison between ratings and functioning. Thus, a patient may be asked to predict how many words they think they will remember from 
Table 2. Mean (s.d.) RBMT memory scores, out of 48, and discrepancy scores between RBMT and pre-test self-ratings, post-test self-ratings and informant ratings. Negative scores reflect over-estimation of functioning. Percent age improvement from pre- to post-ratings is also shown. Asterisks show significant difference from RBMT scores. Hash (\#) indicates the average rating switched from under- to over-estimation of functioning (a total change of 1.34 points), and so improvement scores cannot be calculated, but in any case, represent a negligible change.

discrepancy mean scores (s.d.)

\begin{tabular}{llccrl} 
group & RBMT & self pre-test & self post-test & informant & \% improvement \\
\cline { 2 - 6 } schizophrenia & $30.65(9.51)$ & $0.71(10.78)$ & $-0.63(7.76)$ & $-1.40(11.38)$ & $\# 1.34$ \\
brain injury & $27.31(14.75)$ & $-7.96(13.67)^{*}$ & $-4.08(7.92)^{*}$ & $-3.83(12.89)$ & 47.6 \\
Alzheimer's Disease & $4.11(4.42)$ & $-28.63(10.80)^{*}$ & $-13.22(7.35)^{*}$ & $-11.02(7.79)^{*}$ & 53.8 \\
\hline
\end{tabular}

a list, pre-test (and the same question is put to the informant about the patient). The test is then given and an objective score is obtained. Next, the patient is asked how they think they did.

With the same sample already described, the BI and SCZ patients scored comparably on the RBMT scalein the 'moderately impaired' range. The $\mathrm{AD}$ patients scored in the very impaired range and scored significantly lower than the SCZ $(p<0.001)$ and the BI groups $(p<$ 0.001 ; table 2 ). Of interest is that all groups reported similar levels of functioning on the pre-test rating scale despite clear memory functioning differences.

$\mathrm{BI}$ and $\mathrm{AD}$ patients $\left(t_{1,26}=-13.78, p<0.001\right)$, but not SCZ patients $(t=1,30, p=0.72)$, significantly overestimated their memory functioning before completing the memory test. Following test completion, brain injury $(p=0.01)$ and $\mathrm{AD}$ patients $(p<0.001)$, but not SCZ patients, still significantly over-estimated their memory functioning. In terms of informant ratings, informants for the $\mathrm{AD}(p<0.001)$, but not the brain injury or the SCZ groups, also significantly over-estimated the memory functioning of the respective patients.

Correlation analyses showed that, in the SCZ sample, post-diction $(r=0.58, p=0.001)$ but not prediction ( $r=0.18$, NS) scores correlated significantly with memory scores, whereas informant scores were associated with memory scores at a trend level $(r=0.38, p=0.052)$. In the $\mathrm{BI}$ group, informant $(r=0.57, p<0.005)$ and post-diction $(r=0.89$, $p<0.001)$ ratings correlated highly with actual memory scores, while prediction scores showed a strong trend to be associated with memory scores $(r=0.39, p=0.051)$. Finally, in the $\mathrm{AD}$ group, neither informant nor post-diction scores correlated significantly with memory scores, whereas prediction scores showed a strong negative trend association ( $r=-0.38, p=0.053$ - the lower the RBMT score, the greater the predicted memory performance.

The SCZ patients were poor at pre-rating their own memory performance $(r=0.18)$. The BI group was somewhat more accurate, but the $\mathrm{AD}$ group was particularly poor at predicting memory performance. Indeed, while the SCZ and BI groups showed positive correlations between prediction and actual performance-if they were better, they generally said they were betterthe $\mathrm{AD}$ group showed a negative correlation between the two scores, indicating that as their actual memory scores became worse, they thought they were better.

On average, $\mathrm{AD}$ and $\mathrm{BI}$ patients showed an improvement of approximately 50 per cent in their estimation of functioning, after testing. This would conform to Agnew \& Morris notion of 'mnemonic anosognosia' [24] — which describes an inability to update one's default appraisal of one's memory but with at least some intact ability to detect errors and monitor performance 'on-line'. In other words, this aspect of strategic metacognition was not failing entirely, but the output of this process (presumably being provoked each time there was a memory lapse in the real world) failed to register. The SCZ patients' reasonable estimate of their memory appeared to be dissociable from their insight into the core aspects of their disorder.

A similar approach was taken by Williamson et al. [25] in a small recent study using items from the Neuropsychological Assessment Battery. They compared $10 \mathrm{AD}$ patients with 10 patients suffering from fronto-temporal dementia-who are clinically characterized as severely lacking in 'insight' owing to frontal lobe deficits. They found that, unlike controls, patients consistently over-estimated their performance, the FTD group more so than the AD group (see also [26,27]). Overall, neither showed much variation in estimations pre- versus post-test although, as in our study, the $\mathrm{AD}$ patients did overestimate their performance less on the memory subtest, post-test.

\section{CLINICAL INSIGHT}

As noted above, patients' 'lack of insight' into the experiential and behavioural manifestations of their major mental disorders has been regarded as a defining feature (see $[4,28]$ for reviews). In an effort to clarify the relationship between awareness and psychopathology, Mintz et al. [29] conducted a meta-analysis of 40 relevant studies and found small negative associations between awareness and global, positive and negative symptoms accounting for $7.2,6.3$ and 5.2 per cent of the variance in awareness, respectively. This would strongly suggest that symptomatology plays a small part in, and is relatively independent from, the degree of awareness displayed by SCZ patients.

Several studies have shown that SCZ patients present with less insight than patients with other diagnoses (such as bipolar disorder and major depressive disorder [30], and schizo-affective disorder and mood disorder with and without psychosis [31-33]), or similar levels of insight to bipolar patients, but less than patients with unipolar affective disorder [34]. However, others have found no significant differences between different patient groups [35,36]. 


\section{(a) Mood}

One of the more reliable findings in the literature is the positive correlation between metacognitive ability leading to awareness of illness, and low mood or depression (and between elevated mood and lack of awareness), which has been shown across different patient groups $[4,5,17,18]$. Although findings are variable, many studies have reported that increased awareness in SCZ is associated with greater depressive symptoms [37-42], including a meta-analysis [29]. In this way, poor insight is often conceptualized as a form of denial in order to maintain self-esteem, while good insight is equally regarded as an example of 'depressive realism'. The mechanism underlying this may be conceptualized in signal detection terms as a modulation of response bias. The exception that proves the rule is psychotic depression. Here, a point is reached wherein the usual relationship between low mood and better insight breaks down and the psychosis predominates (see Owen et al. [43]).

\section{(b) Insight and neurocognition}

Several studies have suggested a relationship between intelligence (IQ) and insight in SCZ [44]. The largest individual study to date, which investigated this relationship in over 500 psychosis patients, reported that lack of insight did reflect a generalized cognitive deficit rather than a specific relationship with a particular function [45]. Others claim a more specific association with executive functioning [46,47], particularly as assessed using the Wisconsin card sorting test (WCST). The WCST is generally thought to be a measure of set-shifting ability, where impairment has been hypothesized to be analogous to patients' inability to shift from an previously established 'set' (that of being well); to a more accurate, post-morbid 'set' (of being ill). Cooke et al. [48] examined 29 studies that included a measure of WCST performance and awareness. Of these, there were nine studies in which all WCST measures correlated with awareness and nine studies in which some of them did. All findings were in the anticipated direction, with lower awareness being associated with poorer WCST performance. The most comprehensive and quantitative systematic review and meta-analysis of work in this area [49] suggests that WCST performance has more in common with awareness than other measures, such as IQ or memory, with 13 studies creating a pooled effect size of $r=0.23$.

The pattern of neuropsychological impairment associated with poor insight in first-episode psychosis (FEP) is also unclear. Several studies have found general cognitive impairment to be related to insight [50-52], while others have shown insight to be linked to working memory [53] or verbal memory [45]. Koren et al. [54] were perhaps the first to consider an aspect of metacognition in relation to the clinical concept of insight, that is, the ability to judge one's own performance accurately, and found a relationship with executive functioning.

In summary, clinical insight that includes the ability to re-label symptoms as pathological and to recognize that one is suffering from a disorder that merits treatment, seems to require a degree of executive functioning ability and could be considered to be an executive function in itself. However, within the psychoses, which have been most studied, the magnitude of this effect is modest, suggesting the importance of other contributory variables.

\section{5. 'COGNITIVE INSIGHT'}

More recently, a distinction has been proposed between 'cognitive' insight and clinical insight. This was introduced by Beck et al. [55], and separates a person's awareness and acceptance of illness (clinical insight) from their cognitive style or attributive metacognitive ability - specifically flexibility towards their beliefs, judgements and experiences. The Beck Cognitive Insight Scale (BCIS; [55,56]) is a self-report questionnaire developed to measure cognitive insight. The scale has two theoretically driven and empirically derived factors: self-certainty and self-reflectiveness. Self-certainty refers to overconfidence in the judgements and attributions that one makes (e.g. 'I know better than anyone else what my problems are'), while self-reflectiveness refers to recognition of one's own fallibility and acceptance of correction (e.g. 'Some of the ideas I was certain were true turned out to be false'). A composite index can also be calculated by subtracting the self-certainty score from the self-reflectiveness score.

Research using this scale [57] has shown a correlation between increased severity of delusions and decreased cognitive insight on at least one BCIS subscale [58-61]. However, findings have not been consistent $[62,63]$. The self-reflectiveness subscale has been the less consistent of the two, with one study finding active delusions associated with higher (rather than the predicted lower) self-reflectiveness [64].

The scale has also been used in non-clinical samples with the promise of providing a normative understanding to the insight construct. It has been shown [65] that, among students, theoretical delusion proneness was significantly positively correlated with selfcertainty, but not self-reflectiveness. Comparisons between patients and controls have had mixed results. Self-reflectiveness seems to be lower in deluded patients than for controls, and self-certainty seems to be higher $[64,66]$, as might be expected. Others, however, have found no differences between healthy controls and individuals with SCZ or bipolar disorder on either subscale [67]. There are reasons why the scale is problematic for use in controls. Specifically, several items refer to attitudes towards 'unusual experiences' (e.g. 'my unusual experiences may be due to my being extremely upset or stressed'), which may be interpreted inconsistently by healthy controls, who may not have had such experiences.

Another question for research is what is the relationship between 'cognitive' and 'clinical' insight? The expected positive correlation between clinical scale scores and cognitive insight scores is found in most $[56,61,68]$, but not all $[63,69]$ studies. Much like with clinical insight, it is intuitive to suggest that failures in self-reflection and poor evaluation of one's own thinking may be, at least in part, caused by an inability to perform the complex metacognitive 
operations required and that high levels of selfcertainty may be related to mental inflexibility. Investigation of the neuropsychological correlates of cognitive insight [70] has shown that the composite score was related to verbal learning and memory in a sample of 51 FEP patients. The composite index appears to be related to visual working memory, with self-certainty related to both verbal and visual memory as well as non-preservative errors from the Wisconsin card sorting task ([71]; see also Cooke et al. [68]). An investigation using the Metacognition Assessment Scale [72] found that the 'understanding one's own mind' subscale (which correlated with BCIS total score at $r=0.43$ ) was significantly related to several measures of executive function.

The only published study to date of which we are aware that assessed the relationship between neuropsychological function and cognitive insight in healthy controls found that the index score was significantly correlated with preservative errors on the WCST [73], which is the opposite direction to the results using patient samples.

We recently carried out a study in 107 patients experiencing their first episode of psychosis and 72 healthy controls from South London, as part of the National Institute of Health Research (NIHR) Biomedical Research Centre, Genetics and Psychosis study. Simple correlations showed a positive association between 'cognitive' and 'clinical' insight in patients (Pearson's $r$ ranged from 0.34 to 0.48 ) for the subscales and composite, respectively, and the total SAI-E (Wiffen et al. [74]).

In terms of cognitive functioning, there were some moderate correlations between BCIS scores and a battery of neuropsychological tests, but these were exclusively confined to the patient's group. A regression analysis showed that cognitive variables explained 11.9 per cent of the variance $(p=0.017)$, along with psychotic symptoms scores and IQ. Immediate verbal memory was the only neuropsychological variable to contribute independently to the final model.

While metacognition in the form of self-reflection and self-certainty may reflect some sort of cognitive style in healthy participants that may put them at risk of psychotic disorder, it may not necessarily reflect the same mechanism as in patients. Indeed, the present results suggest that the style is moderated by memory (and positive psychotic symptoms) in patients, while there is little or no evidence of this in healthy controls.

There was a small trend towards a correlation between the composite score and depression score. Results in the literature on this have again been mixed $[63,75]$. The relationship between depression and cognitive insight parallels the same finding for clinical insight [29]. Conceptually, it is more likely that the correlation with cognitive insight is driven by self-reflectiveness rather than certainty since the former can take on a ruminative quality typical of depressive thinking. However, the association found here is relatively small $(r=0.21)$, so should be interpreted with caution.

In sum, there is still much work to be done to establish whether there is a general thinking style involving self-reflectiveness and self-certainty captured by the
BCIS that is analogous to insight into psychotic illness. One conclusion from the work reviewed here is that despite suffering from delusions and other phenomena, psychotic patients show surprisingly little evidence for a gross disturbance in this thinking style or an overarching metacognitive failure. However, this may be due to inherent difficulties in measuring such concepts and possible confounds such as mood and intellectual functions (especially memory). There is also the uncomfortable fact that assessing cognitive insight with questionnaires like the BCIS threatens an infinite regress: you must be able to reflect accurately on your ability to reflect accurately.

\section{INSIGHT AND SELF-REFLECTION}

One of the issues raised by the BCIS work is the difficulty in finding a normal equivalent of clinical insight. After all, asking a self-aware healthy person to perform the metacognitive task of saying whether they suffer from a mental illness or symptoms thereof should lead to an emphatic 'no', while the patient with SCZ who lacks all insight into their condition will give the same response, with the same certainty. However, self-reflection directed at personality traits is something everyone, in principle, should be able to perform meaningfully. And the extent to which this process is equivalent to illness awareness will be considered later.

Work by Nick Bedford for his $\mathrm{PhD}$ [76-78] addressed this question using a variety of novel paradigms. A simple starting point was to examine the acceptance of trait adjectives by patients and controls, both positive and negative, some of which were related to mental illness, but in a way that might be seen as applicable to many people, with or without a clinical psychiatric diagnosis. He carefully constructed a list of 96 trait adjectives matched on important psycholinguistic parameters and carried out a number of memory and evaluative studies using them. Examples included: Mental illness-related: unstable, crazy, disordered, psychotic; Negative: evil, cruel, hostile, dishonest; Positive: wonderful, great, special, clever; Physical illness-related terms were also included to act as a control for psychiatric illness-related terms: diabetic, cancerous, paralysed, etc. Note there is no attempt to relate judgement to a 'gold standard'.

However, one of the most striking results came from simply contrasting the extent to which demographically matched participants would admit to the trait applying to themselves, on the Trait Ownership Scale scored from 0 (not at all) to 4 (extremely) (figure 2). The study's participants comprised healthy volunteers $(n=28)$ and SCZ patients with good $(n=14)$ and poor insight $(n=12)$, according to standard scales. From inspection of the figure, it appears that the patients who are repudiating any mental illness in themselves show variation according to the way the illness is described. So being 'unwell' or 'ill' seems to be more acceptable in the poor insight than the good insight patients, yet being 'crazy' seems to be abhorrent to poor insight patients while quite acceptable to good insight patients and even some healthy volunteers. The technical term 'schizophrenic' is, not 


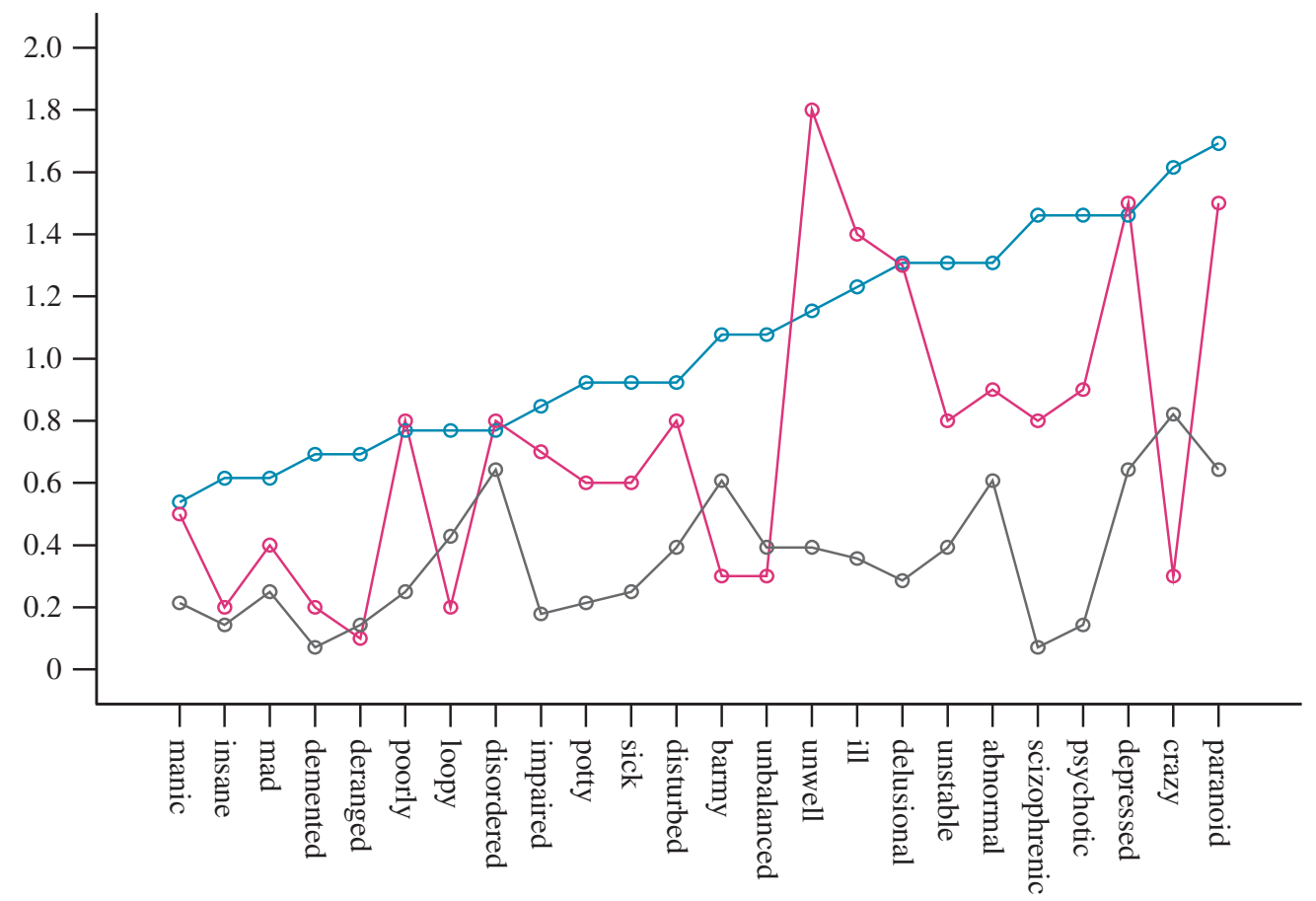

Figure 2. Mean Trait Ownership Scale Ratings for individual mental illness traits. Blue line, good insight $(n=14)$; magenta line, poor insight $(n=12)$; grey line, healthy controls $(n=28)$.

surprisingly acceptable to the good insight patients, not at all to the controls and yet is endorsed to an intermediate degree by the remaining patients.

Participants were also asked to rate the desirability of the traits on a similar 5-point scale. It would be reasonable to hypothesize that social and interpersonal factors affect trait ownership and this complicates (biases) the assessment of metacognitive 'accuracy' in determining self-reflective ability-e.g. self-serving and other biases [79]. Overall, there was a tendency for ownership and desirability to covary, especially for negative traits-i.e. the less desirable a trait, the less strongly it was 'owned'. Mental illness trait desirability did not correlate with ownership at all in healthy subjects $(r=-0.02)$, but correlated in the good insight ('accepting') patients at $r=0.28$ (NS) and $r=0.45$ (NS) in the poor insight ('denial') patients, suggesting that perceived desirability may have been one but certainly not the most powerful driver for mental illness trait ownership [77,78]. Correlations between desirability and positive trait ownership were, however, especially strong in poor insight patients $(r=0.82, p<0.05)$, but not the other groups.

Nevertheless, there is still the concern that metacognitive processes aimed at personal illness evaluation inevitably ending up requiring the individual to 'admit' to something bad about themselves. Being ill in some way is never a good thing. Hence there is a potential confound in all such self-reflection tasks. We attempted to tackle this by devising vignettes in which, paradoxically, the protagonist stood to benefit if they admitted that they had a mental illness or condition [77]. For example, Tom, a person with mental health problems, gets a Council Tax bill. He fears that he will struggle to pay it. However, the bill is slightly lower for people who are unemployed and much lower for people who have psychiatric problems. The participant is then given a number of options on how they would proceed if they were Tom, ranging from admitting he has psychiatric problems and paying the lower amount to paying the amount in full. In short, all participants were influenced by the relative advantageousness of admitting to mental health problems, but the SCZ patients less so than controls. There was no clear difference between the low and high insight patients.

To conclude, it appears that many patients with mental illness are reluctant to acknowledge their mental illness traits or history. This does not seem to be easily explained on the basis of perceived benefits/ losses. Instead, the possibilities include a 'genuine' inability to reflect accurately one's life story or current mental contents (a failure of strategic metacognition), or the activity of self-reflection may be performed but the appraisal of the material, the 'object' under scrutiny, is systematically biased or at fault (a failure of attributive metacognition).

\section{CLINICAL INSIGHT AND BRAIN STRUCTURE}

Imaging findings first suggested an association between poor insight and reduced total brain volume $[80-82]$, reduced frontal lobe volume [83-86], reduced cingulate gyrus and temporal lobe grey matter volume $[87,88]$. There are now several published studies of this topic, but much variation in the location of brain-insight correlates and in some instances a failure to identify any brain abnormalities associated with poor insight $[11,35,89]$ (table 3 ). One explanation for this inconsistency could be the use of different image analysis techniques such as region of interest measurements or voxel-based morphometry (VBM) methods of analysis $[88,89,91]$. In some studies, a single insight assessment item has 
Table 3. Summary of neuroimaging studies in relation to insight in psychosis. Magnetic resonance imaging (MRI) unless otherwise stated. BIS, Birchwood insight scale; FE, first episode; CT, computed tomography; ITAQ, insight and treatment attitudes questionnaire; OPs, outpatient; PANSS, positive and negative symptoms of schizophrenia scale; PSE, present-state examination; SAI-E, schedule for the assessment of insight (expanded); SUMD, scale for the assessment of unawareness of mental disorder; Sz, schizophrenia patients; FE, first episode; BIS, Birchwood insight scaleVBM, voxel-based morphometry.

\begin{tabular}{|c|c|c|c|}
\hline $\begin{array}{l}\text { first authors (year) } \\
\text { (reference) }\end{array}$ & patients & $\begin{array}{l}\text { main findings (association with reduced insight } \\
\text { and brain indices) }\end{array}$ & $\begin{array}{l}\text { insight } \\
\text { measure }\end{array}$ \\
\hline Antonius et al. (2011) [90] & $\mathrm{Sz}(n=36)$ & fronto-temporal / temp-parietal white matter & SUMD \\
\hline Berge et al. (2010) [91] & $\mathrm{Sz}, \mathrm{FE}(n=21)$ & $\begin{array}{l}\downarrow \text { medial frontal bilat; sup frontal, R inf temporal, } \\
\text { inf frontal grey; VBM }\end{array}$ & SUMD \\
\hline Buchy et al. (2010) [92] & $\mathrm{Sz}, \mathrm{FE}(n=79)$ & L frontal, temp (and parietal) cortical thinning & SUMD \\
\hline Morgan et al. (2010) [93] & psychosis, FE $(n=82)$ & $\begin{array}{l}\downarrow \text { posterior cingulate and right } \\
\text { precuneus/cuneus grey density }\end{array}$ & SAI-E \\
\hline Cooke et al. (2008) [88] & Sz/Sz Aff, OPs $(n=52)$ & $\downarrow$ L temporal and parietal; precuneus grey; VBM & SAI-E/BIS \\
\hline Sapara et al. (2007) [85] & Sz, chronic, OPs $(n=28)$ & $\downarrow$ prefrontal grey & SAI-E \\
\hline Shad et al. (2006) [86] & $\mathrm{Sz}(n=14)$ & $\begin{array}{l}\downarrow \mathrm{R} \text { dorsolateral prefrontal and } \downarrow \text { awareness; } \\
\uparrow \mathrm{R} \text { orbitofrontal and abnormal attributions }\end{array}$ & SUMD \\
\hline Bassitt et al. (2006) [89] & $\mathrm{Sz}(n=50)$ & no assoc. with prefrontal grey/white vols & SUMD \\
\hline McEvoy et al. (2006) [81] & $\mathrm{Sz}(n=251)$ & $\downarrow$ total grey/white/whole brain & ITAQ \\
\hline Ha et al. (2004) [87] & Sz OPs $(n=35)$ & $\begin{array}{l}\downarrow \text { grey L post / } \mathrm{R} \text { ant. cingulate and bilateral inf. } \\
\text { temporal }\end{array}$ & PANSS \\
\hline Rossell et al. (2003) [11] & Sz (males) $(n=78)$ & no association whole brain, white / grey vols & SAI-E \\
\hline Laroi et al. (2000) [83] & $\mathrm{Sz}(n=20)$ & frontal lobe atrophy (CT) & SUMD \\
\hline Flashman et al. (2001) [84] & Sz spectrum $(n=30)$ & $\downarrow$ frontal lobe volume & SUMD \\
\hline Flashman et al. (2000) [80] & Sz spectrum $(n=30)$ & $\downarrow$ whole brain volume & SUMD \\
\hline David et al. (1995) [35] & $\begin{array}{l}\text { mixed psychosis } \\
\quad(n=128)\end{array}$ & no association with ventricular vol. (CT) & PSE \\
\hline Takai et al. (1992) [82] & Sz, chronic $(n=22)$ & ventricular enlargement & PANSS \\
\hline
\end{tabular}

been used $[35,82,87]$, while in the others, insight schedules were employed. The most recent studies have started to employ novel imaging methods, for example, cortical thickness [92] and white matter integrity [90].

Nevertheless, frontal abnormalities predominate. In our study, Kevin Morgan et al. [93] used VBM methods in a large sample of FEP patients and found deficits particularly with respect to attribution of symptoms in cingulate cortex, perhaps related to the midline cerebral system for self-processing $[94,95]$ as well as right posterior deficits - reminiscent of regions implicated in neurological cases of anosognosia of hemiplegia and neglect [96]. Damage to any of these putative systems could potentially account for impaired self-awareness. Research in other psychiatric disorders is needed before we can say whether or not these findings are disorder-specific.

\section{(a) Functional imaging}

The functional correlates of self-reflection have been the topic of several imaging experiments. These have been carefully reviewed and summarized [94,95] and found to reveal a fairly consistent picture, namely that there is a 'cortical midline system' that is reliably engaged in such tasks encompassing the medial frontal (ventro-medial, Brodmann Areas (BA) 10,11 and dorso-medial, BA 9) and cingulate cortex. Furthermore, Fleming et al. [97] showed that metacognitive ability on a perceptual task was related to grey mater volume in BA 10. A quantitative meta-analysis was performed by van der Meer et al. [98], which highlighted the anterior portion of the system as most often engaged when self-appraisal was contrasted to other-appraisal. This region overlaps with that noted in structural imaging studies in SCZ as differentiating low and high insight patients - a tantalizing hint that there might be structural-functional convergence. This prompted further work in which 11 of the 12 patients studied by Bedford mentioned above also underwent functional MRI during a version of the self-reflection-attribution of traits task. We hypothesized that the cortical midline system would be less active in self- versus other appraisal when considering the self-relevance of trait adjectives (with each also contrasted to a letter monitoring baseline condition).

Results of this ongoing study [99] seem to suggest that the medial frontal cortex is indeed critical to abnormal self-appraisal in patients with SCZ, since this region was the only one to reach statistical threshold for the interaction between patients and controls and self- versus other appraisal (taking all trait terms together). As shown in figure 3, activation in the left superior frontal gyrus (BA 9) close to the midline (Talairach coordinates-6,53,32) increased when controls considered themselves as opposed to a famous 'other' (in this case, Tony Blair), while patients failed to show this increase-which we interpret as demonstrating a failure to differentiate sufficiently between self and other metacognitive processing. These findings are in line with recent fMRI work [100], which showed that patients with SCZ activated less medial prefrontal regions and relatively more mid and posterior cingulate cortex during a similar selfreflection task to the one used by Bedford et al., the difference being that in this task the patient's mother 

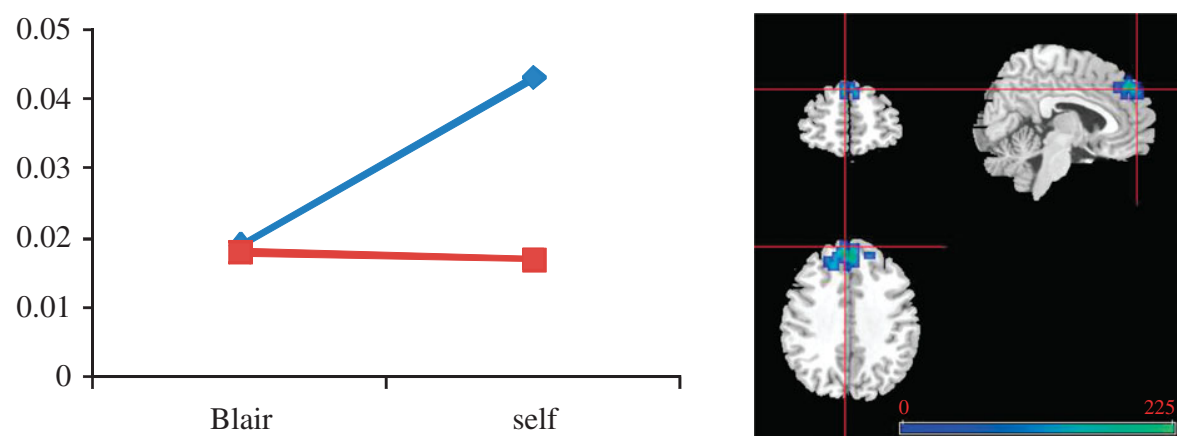

Figure 3. Functional MRI study showing region of significant activation difference between schizophrenia patients (red boxes) and healthy controls (blue trapezoids) during self-reflection task for self versus Blair. Left superior frontal gyrus (BA9) $-x, y, z$ coordinates: $6,53,32$ [57 voxels].

was the 'other person' comparator. Similar central midline brain regions are highlighted in an fMRI study of students scoring highly on a questionnaire recording psychotic experiences, but seem to show increased rather than reduced activation [101].

\section{CONCLUSIONS}

It is possible to place the clinical, especially psychiatric concept of insight into illness within a metacognitive framework. From this a number of fairly reliable associations emerge: worse symptoms tends to go with worse insight, with the exception of mood (lower mood and better insight); in contrast, better cognitive ability, both general (IQ) and specific (executive function; memory) is associated with better insight. The effect of low mood may be mediated by a more conservative response bias, or as some clinicians would have it, may reflect the consequences of insight into a disorder. This is an area ripe for research and may exploit the emerging notion of 'cognitive insight', which seeks to provide a normative metacognitive framework relevant to psychiatry. Hence, the effects of mood on metacognition can be studied naturalistically without reference to actual disorder. The association between cognitive impairment and poor insight may point to common information processing deficits underlying impaired metacognition and self-refection/appraisal.

Exploration of failures of metacognition across different neuropsychiatric conditions (SCZ, AD and brain injury) reveals that Alzheimer and brain-injured patients demonstrate on-line awareness of memory problems, but we inferred a failure to use this to update knowledge about memory ability. We also showed that there could be marked variability across diagnostic groups both within and across domains (i.e. memory versus symptom awareness). This fractionation, even within the narrow sphere of psychotic symptoms, arguably raises questions about the modularity or content specificity of metacognition in general. That is to say, studying failures of metacognition may illuminate healthy metacognition. There are also parallels to be drawn between the notion of insight in psychopathology as a relational concept - there are potentially many objects of insight and good insight or accurate metacognition may pertain to some but not all-which accords well with the non-clinical literature on meta-memory [102].
This principle may be extended into the neurological instantiation of metacognition, which again, may be revealed more strongly by inference from pathological systems. A clear cerebral localization for a system supporting self-reflection centring on the medial frontal and posterior medial cortex is becoming accepted. Summarizing structural neuroimaging findings in relation to insight in psychotic disorders, particularly $S C Z$, we find that a clear pattern has yet to emerge despite several studies using different imaging modalities. However, taking some of the findings along with preliminary functional imaging work of selfreflection in patients presented here, points to an important role for dorso-medial frontal cortex in mediating metacognition in relation to psychopathology.

\section{REFERENCES}

1 Saxe, R. \& Offen, S. 2010 Seeing ourselves: what vision can teach us about metacognition. In Metacognition and severe adult mental disorders (eds G. Dimaggio \& P. H. Lysaker), pp. 13-30. Hove, East Sussex: Routledge.

2 Prigatano, G. P. 2009 The study of anosognosia. New York, NY: Oxford University Press.

3 David, A. S. 1990 Insight and psychosis. Brit. F. Psychiat. 156, 798-808. (doi:10.1192/bjp.156.6.798)

4 Amador, X. F. \& David, A. S. (eds) 2004 Insight and psychosis: awareness of illness in schizophrenia and related disorders, 2nd edn. Oxford, UK: Oxford University Press.

5 Markova, I. S. 2005 Insight in psychiatry. Cambridge, UK: Cambridge University Press.

6 Amador, X. F., Strauss, D. H., Yale, S. A. \& Gorman, J. M. 1993 Assessment of insight in psychosis. Am. F. Psychiat. 150, 873-879.

7 Wiffen, B. D. R., Rabinowitz, J., Lex, A. \& David, A. S. 2010 Correlates, change and 'state or trait' properties of insight in schizophrenia. Schizophr. Res. 122, 94-103. (doi:10.1016/j.schres.2010.03.005)

8 Sanz, M., Constable, G., Lopez-Ibor, I., Kemp, R. \& David, A. S. 1998 A comparative study of insight scales and their relationship to psychopathological and clinical variables. Psychol. Med. 28, 437-446. (doi:10. 1017/S0033291797006296)

9 Gilleen, J., Greenwood, K. \& David, A. S. 2009 Anosognosia in schizophrenia and other neuropsychiatric disorders: similarities and differences. In The study of anosognosia (ed. G. P. Prigatano), pp. 255-290. Oxford, UK: Oxford University Press.

10 Gilleen, J., Greenwood, K. \& David, A. S. 2010 Lack of insight and awareness in schizophrenia and 
neuropsychiatric disorders. In Neuropsychiatric disorders (eds K. Myoshi, Y. Morimura \& K. Maeda), pp. 3349. Tokyo, Japan: Springer.

11 Rossell, S. L., Coakes, J., Shapleske, J. \& Woodruff, P. W. R. 2003 Insight: its relationship with cognitive function, brain volume and symptoms in schizophrenia. Psychol. Med. 33, 111-119.

12 Kircher, T. T. J., Koch, K., Stottmeister, F. \& Durst, V. 2007 Metacognition and reflexivity in patients with schizophrenia. Psychopathology 40, 254-260. (doi:10. 1159/000101730)

13 Medalia, A. \& Thysen, J. 2008 Insight into neurocognitive dysfunction in schizophrenia. Schizophr. Bull. 34, 1221-1230. (doi:10.1093/schbul/sbm144)

14 Bayard, S., Capdevielle, D., Boulenger, J.P. \& Raffard, S. 2009 Dissociating self-reported cognitive complaint from clinical insight in schizophrenia. Eur. Psychiat. 24, 251-258. (doi:10.1016/j.eurpsy.2008.12.010)

15 McGlynn, S. M. \& Schacter, D. L. 1989 Unawareness of deficits in neuropsychological syndromes. F. Clin. Exp. Neuropsychol. 11, 143-205. (doi:10.1080/01688 638908400882)

16 Teasdale, T. W. et al. 1997 Subjective experience in brain injured patients and their close relatives: a European brain injury questionnaire study. Brain Injury 11, 543-564. (doi:10.1080/026990597123250)

17 Clare, L. 2004 Awareness in early-stage Alzheimer's disease: a review of methods and evidence. Brit. $\mathcal{F}$. Clin. Psychol. 43, 177-196. (doi:10.1348/014466504 323088042)

18 Clare, L. 2004 The construction of awareness in earlystage Alzheimer's disease: a review of concepts and models. Brit. F. Clin. Psychol. 43, 155-175. (doi:10. 1348/014466504323088033)

19 Vasterling, J. J., Seltzer, B., Foss, J. W. \& Vanderbrook, V. 1995 Unawareness of deficit in Alzheimer's disease. Domain-specific differences and disease correlates. Neuropsychol. Neuropsychol. Behav. Neurol. 8, 26-32.

20 Gilleen, J., Greenwood, K. \& David, A. S. 2011 Domains of awareness in schizophrenia. Schizophr. Bull. 37, 61-72. (doi:10.1093/schbul/sbq100)

21 Burgess, P. W., Alderman, N., Emslie, H., Evans, J. J. \& Wilson, B. A. 1996 The dysexecutive questionnaire. In Behavioural assessment of the dysexecutive syndrome. Bury St. Edmunds, UK: Thames Valley Test Company.

22 Clare, L., Wilson, B. A., Carter, G., Roth, I. \& Hodges, J. R. 2002 Assessing awareness in early-stage Alzheimer's disease: Development and piloting of the Memory Awareness Rating Scale. Neuropsychol. Rehab. 12, 341-362. (doi:10.1080/09602010244000129)

23 Wilson, B., Cockburn, J. \& Baddeley, A. 1985 The Rivermead behavioural memory test (RBMT). Reading, MA: Thames Valley Test Company.

24 Agnew, S. K. \& Morris, R. G. 1998 The heterogeneity of anosognosia for memory impairment in Alzheimer's disease: a review of the literature and a proposed model. Aging Mental Health 2, 7-19. (doi:10.1080/ 13607869856876)

25 Williamson, C., Alcantar, O., Rothlind, J., CahnWeiner, D., Miller, B. L. \& Rosen, H. J. 2010 Standardised measurement of self-awareness deficits in FTD and AD. F. Neurol. Neurosurg. Psychiat. 81, 140-145. (doi:10.1136/jnnp.2008.166041)

26 Banks, S. J. \& Weintraub, S. 2009 Generalized and symptom-specific insight in behavioral variant frontotemporal dementia and primary progressive aphasia. 7. Neuropsychiatr. Clin. Neurosci. 21, 299-306. (doi:10. 1176/appi.neuropsych.21.3.299)

27 O'Keeffe, F. M., Murray, B., Coen, R. F., Dockree, P. M., Bellgrove, M. A., Garavan, H., Lynch, T. \&
Robertson, I. H. 2007 Loss of insight in frontotemporal dementia, corticobasal degeneration and progressive supranuclear palsy. Brain 130, 753-764. (doi:10.1093/ brain/awl367)

28 Osatuke, K., Ciesla, J., Kasckow, J. W., Zisook, S. \& Mohamed, S. 2008 Insight in schizophrenia: a review of etiological models and supporting research. Compr. Psychiat. 49, 70-77. (doi:10.1016/j.comppsych.2007. 08.001)

29 Mintz, A. R., Dobson, K. S. \& Romney, D. M. 2003 Insight in schizophrenia: a meta-analysis. Schizophr. Res. 61, 75-88. (doi:10.1016/S0920-9964(02)00316-X)

30 Michalakeas, A., Skoutas, C., Charalambous, A., Peristeris, A., Marinos, V., Keramari, E. \& Theologou, A. 1994 Insight in schizophrenia and mood disorders and its relation to psychopathology. Acta. Psychiat. Scand. 90, 46-49. (doi:10.1111/j.1600-0447.1994. tb01554.x)

31 Ghaemi, S. N. \& Rosenquist, K. J. 2004 Is insight in mania state-dependent?: a meta-analysis. f. Nerv. Ment. Dis. 192, 771-775. (doi:10.1097/01.nmd. 0000145036.76435.c3)

32 Amador, X. F., Flaum, M., Andreasen, N. C., Strauss, D. H., Yale, S. A., Clark, S. C. \& Gorman, J. M. 1994 Awareness of illness in schizophrenia and schizoaffective and mood disorders. Arch. Gen. Psychiat. 51, 826-836. (doi:10.1001/archpsyc.1994.03950100074007)

33 Pini, S., Cassano, G. B., Dell'Osso, L. \& Amador, X. F. 2001 Insight into illness in schizophrenia, schizoaffective disorder, and mood disorders with psychotic features. Am. F. Psychiat. 158, 122-125. (doi:10.1176/ appi.ajp.158.1.122)

34 Varga, M., Magnusson, A., Flekkoy, K., David, A. S. \& Opjordsmoen, S. 2007 Clinical and neuropsychological correlates of insight in schizophrenia and bipolar I disorder: does diagnosis matter? Compr. Psychiat. 28, 583-591.

35 David, A., van Os, J., Jones, P., Harvey, I., Foerster, A. \& Fahy, T. 1995 Insight and psychotic illness. Crosssectional and longitudinal associations. Brit. F. Psychiat. 167, 621-628. (doi:10.1192/bjp.167.5.621)

36 Cuesta, M. J., Peralta, V. \& Zarzuela, A. 2000 Reappraising insight in psychosis. Multi-scale longitudinal study. Brit. F. Psychiat. 177, 233-240. (doi:10.1192/ bjp.177.3.233)

37 Carroll, A., Fattah, S. \& Clyde, Z. 1999 Correlations of insight and insight change in schizophrenia. Schizophr. Res. 35, 247-253. (doi:10.1016/S0920-9964(98) 00142-X)

38 Smith, T. E., Hull, J. W., Israel, L. M. \& Willson, D. F. 2000 Insight, symptoms, and neurocognition in schizophrenia and schizoaffective disorder. Schizophr. Bull. 26, 193-200.

39 Pyne, J. M., Bean, D. \& Sullivan, G. 2001 Characteristics of patients with schizophrenia who do not believe they are mentally ill. F. Nerv. Ment. Dis. 189, 146-153. (doi:10.1097/00005053-200103000-00002)

40 Moore, O., Cassidy, E., Carr, A. \& O’Callaghan, E. 1999 Unawareness of illness and its relationship with depression and self-deception in schizophrenia. Eur. Psychiat. 14, 264-269. (doi:10.1016/S0924-9338(99) 00172-8)

41 Iqbal, Z., Birchwood, M., Chadwick, P. \& Trower, P. 2000 Cognitive approach to depression and suicidal thinking in psychosis. 2 . Testing the validity of a social ranking model. Brit. f. Psychiat. 177, 522-528. (doi:10.1192/bjp.177.6.522)

42 Schwartz, R. C. 2001 Self-awareness in schizophrenia: its relationship to depressive symptomatology and broad psychiatric impairments. F. Nerv. Ment. Dis. 
189, 401-403. (doi:10.1097/00005053-20010600000010)

43 Owen, G. S., Richardson, G., David, A. S., Szmukler, G., Hayward, P. \& Hotopf, M. 2009 Mental capacity, diagnosis, and insight in psychiatric inpatients: a cross-sectional study. Psychol. Med. 39, 1389-1398. (doi:10.1017/S0033291708004637)

44 David, A. S. 1999 'To see ourselves as others see us.' Aubrey Lewis's Insight. Brit. F. Psychiat. 174, 210-216. (doi:10.1192/bjp.175.3.210)

45 Keshavan, M. S., Rabinowitz, J., DeSmedt, G., Harvey, P. D. \& Schooler, N. 2004 Correlates of insight in first episode psychosis. Schizophr. Res. 70, 187-194. (doi:10.1016/j.schres.2003.11.007)

46 Young, D. A., Zakzanis, K. K., Bailey, C., Davila, R., Griese, J., Sartory, G. \& Thom, A. 1998 Further parameters of insight and neuropsychological deficit in schizophrenia and other chronic mental disease. F. Nerv. Ment. Dis. 186, 44-50. (doi:10.1097/000050 53-199801000-00007)

47 Young, D. A., Campbell, Z., Zakzanis, K. K. \& Weinstein, E. 2003 A comparison between an interview and a self-report method of insight assessment in chronic schizophrenia. Schizophr. Res. 63, 103-109. (doi:10.1016/S0920-9964(02)00378-X)

48 Cooke, M. A., Peters, E. R., Kuipers, E. \& Kumari, V. 2005 Disease, deficit or denial? Models of poor insight in psychosis. Acta. Psychiat. Scand. 112, 4-17. (doi:10. 1111/j.1600-0447.2005.00537.x)

49 Aleman, A., Agrawal, N., Morgan, K. D. \& David, A. S. 2006 Insight in psychosis and neuropsychological function: meta-analysis. Brit. F. Psychiat. 189, 204-212. (doi:10.1192/bjp.189.3.204)

50 McEvoy, J. P., Johnson, J., Perkins, D., Lieberman, J. A., Hamer, R. M., Keefe, R. S., Tohen, M., Glick, I. D. \& Sharma, T. 2006 Insight in first-episode psychosis. Psychol. Med. 36, 1385-1393. (doi:10.1017/ S0033291706007793)

51 Morgan, K. D. \& David, A. S. 2004 Neuropsychological studies of insight in patients with psychotic disorders. In Insight and psychosis: awareness of illness in schizophrenia and related disorders (eds X. F. Amador \& A. S. David), pp. 177-193, 2nd edn. New York, NY: Oxford University Press.

52 Parellada, M. et al. 2011 Trait and state attributes of insight in first episodes of early-onset schizophrenia and other psychoses: a 2-year longitudinal study. Schizophr. Bull. 37, 38-51. (doi:10.1093/schbul/sbq109)

53 Mutsatsa, S. H., Joyce, E. M., Hutton, S. B. \& Barnes, T. R. 2006 Relationship between insight, cognitive function, social function and symptomatology in schizophrenia: the West London first episode study. Eur. Arch. Psychiat. Clin. Neuros. 256, 356-363. (doi:10.1007/ s00406-006-0645-7)

54 Koren, D., Seidman, L. J., Poyurovsky, M., Goldsmith, M., Viksman, P., Zichel, S. \& Klein, E. 2004 The neuropsychological basis of insight in first-episode schizophrenia: a pilot metacognitive study. Schizophr. Res. 70, 195-202. (doi:10.1016/j.schres.2004.02.004)

55 Beck, A. T. \& Warman, D. M. 2004 Cognitive insight: theory and assessment. In Insight and psychosis: awareness of illness in schizophrenia and related disorders (eds X. F. Amador \& A. S. David), pp. 79-87, 2nd edn. New York, NY: Oxford University Press.

56 Beck, A. T., Baruch, E., Balter, J. M., Steer, R. A. \& Warman, D. M. 2004 A new instrument for measuring insight: the Beck cognitive insight scale. Schizophr. Res. 68, 319-329. (doi:10.1016/S0920-9964(03)00189-0)

57 Riggs, S. E., Grant, P. M., Perivoliotis, D. \& Beck, A. T. 2012 Assessment of cognitive insight: a qualitative review. Schizophr. Bull. 38, 338-350. (doi:10.1093/ schbul/sbq085)

58 Bora, E., Erkan, A., Kayahan, B. \& Veznedaroglu, B. 2007 Cognitive insight and acute psychosis in schizophrenia. Psychiat. Clin. Neurosci. 61, 634-639. (doi:10.1111/j.1440-1819.2007.01731.x)

59 Buchy, L., Malla, A., Joober, R. \& Lepage, M. 2009 Delusions are associated with low self-reflectiveness in first-episode psychosis. Schizophr. Res. 112, 187-191. (doi:10.1016/j.schres.2009.03.019)

60 Engh, J. A. et al. 2009 Delusions are associated with poor cognitive insight in schizophrenia. Schizophr. Bull. 36, 830-835. (doi:10.1093/schbul/sbn193)

61 Pedrelli, P., McQuaid, J. R., Granholm, E., Patterson, T. L., McClure, F., Beck, A. T. \& Jeste, D.V. 2004 Measuring cognitive insight in middle-aged and older patients with psychotic disorders. Schizophr. Res. 71, 297-305. (doi:10.1016/j.schres.2004.02.019)

62 Favrod, J., Zimmermann, G., Raffard, S., Pomini, V. \& Khazaal, Y. 2008 The Beck Cognitive Insight Scale in outpatients with psychotic disorders: further evidence from a French-speaking sample. Can. F. Psychiat. 53, 783-787.

63 Tranulis, C., Lepage, M. \& Malla, A. 2008 Insight in first episode psychosis: who is measuring what? Early Interv. Psychiat. 2, 34-41. (doi:10.1111/j.1751-7893. 2007.00054.x)

64 Warman, D. M., Lysaker, P. H. \& Martin, J. M. 2007 Cognitive insight and psychotic disorder: the impact of active delusions. Schizophr. Res. 90, 325-333. (doi:10.1016/j.schres.2006.09.011)

65 Warman, D. M. \& Martin, J. M. 2006 Cognitive insight and delusion proneness: an investigation using the Beck cognitive insight scale. Schizophr. Res. 84, 297-304. (doi:10.1016/j.schres.2006.02.004)

66 Martin, J. M., Warman, D. M. \& Lysaker, P. H. 2010 Cognitive insight in non-psychiatric individuals and individuals with psychosis: an examination using the Beck cognitive insight scale. Schizophr. Res. 121, 39-45. (doi:10.1016/j.schres.2010.03.028)

67 Engh, J. A., Friis, S., Birkenaes, A., Jonsdottir, H., Ringen, P., Ruud, T., Sundet, K. S., Opjordsmoen, S. \& Andreassen, O. A. 2007 Measuring cognitive insight in schizophrenia and bipolar disorder: a comparative study. BMC Psychiat. 7, 71. (doi:10.1186/1471-244X-7-71)

68 Cooke, M. A., Peters, E. R., Fannon, D., Aasen, I., Kuipers, E. \& Kumari, V. 2010 Cognitive insight in psychosis: the relationship between self-certainty and self-reflection dimensions and neuropsychological measures. Psychiat. Res. 178, 284-289. (doi:10.1016/j. psychres.2009.05.009)

69 Greenberger, C. \& Serper, M. R. 2010 Examination of clinical and cognitive insight in acute schizophrenia patients. F. Nerv. Ment. Dis. 198, 465-469. (doi:10. 1097/NMD.0b013e3181e4f35d)

70 Lepage, M., Buchy, L., Bodnar, M., Bertrand, M.-C., Joober, R. \& Malla, A. 2008 Cognitive insight and verbal memory in first episode of psychosis. Eur. Psychiat. 23, 368-374. (doi:10.1016/j.eurpsy.2008.02.003)

71 Orfei, M. D., Caltagirone, C., Cacciari, C., Assogna, F. \& Spalletta, G. 2011 The neuropsychological correlates of cognitive insight in healthy participants. App. Cogn. Psychol. 25, 927-932. (doi:10.1002/acp.1771)

72 Lysaker, P. H., Warman, D. M., Dimaggio, G., Procacci, M., LaRocco, V. A., Clark, L. K., Dike, C. A. \& Nicolo, G. 2008 Metacognition in schizophrenia: associations with multiple assessments of executive function. F. Nerv. Ment. Dis. 196, 384-389. (doi:10.1097/NMD.0b013e3181710916)

73 Orfei, M. D., Spoletini, I., Banfi, G., Caltagirone, C. \& Spalletta, G. 2010 Neuropsychological correlates of 
cognitive insight in schizophrenia. Psychiat. Res. 178, 51-56. (doi:10.1016/j.psychres.2009.05.013)

74 Wiffen, B. D. R., O’Connor, J. A., Russo, M., Falcone, A., Sood, P., Taylor, H., Aas, M., Murray, R. M. \& David, A. S. In preparation. The neuropsychological basis of cognitive insight in first episode psychosis and healthy controls.

75 Colis, M., Steer, R. \& Beck, A. T. 2006 Cognitive insight in inpatients with psychotic, bipolar, and major depressive disorders. F. Psychopathol. Behav. Assess. 28, 242-249. (doi:10.1007/s10862-005-9012-7)

76 Bedford, N. J. 2009 Denial of illness in schizophrenia as a disturbance of insight and self-awareness. Schizophrenia-academic dissertations [MESH]. Institute of Psychiatry Theses PhD, University of London. System No 001296598. pp. 361. See http://library.kcl.ac.uk/.

77 Bedford, N. \& David, A. 2008 Impression management of deficiencies and denial of illness in schizophrenia: reluctance to expose mental illness unmoderated by its level of advantageousness. Schizophr. Res. 102(suppl 2), 117. (doi:10.1016/S0920-9964(08)70353-0)

78 Bedford, N. \& David, A. 2009 Poor insight in psychosis: cognitive deficit or bias? Schizophr. Bull. 35(suppl 1), 281.

79 Pronin, E. 2008 How we see ourselves and how we see others. Science 320, 1177-1180. (doi:10.1126/science. 1154199)

80 Flashman, L. A., McAllister, T. W., Andreasen, N. C. \& Saykin, A. J. 2000 Smaller brain size associated with unawareness of illness in patients with schizophrenia. Am. F. Psychiat. 157, 1167-1169. (doi:10.1176/appi. ajp.157.7.1167)

81 McEvoy, J. P., Johnson, J., Perkins, D., Lieberman, J. A., Hamer, R. M., Keefe, R. S., Tohen, M., Glick, I. D. \& Sharma, T. 2006 Insight in first-episode psychosis. Psychol. Med. 36, 1385-1393. (doi:10.1017/ S0033291706007793)

82 Takai, A., Uematsu, M., Ueki, H., Sone, H. \& Kaiya, H. 1992 Insight and its related factors in chronic schizophrenic patients: a preliminary study. Eur. F. Psychiat. 6, 159-170.

83 Laroi, F., Fannemel, M., Ronneberg, U., Flekkoy, K., Opjordsmoen, S., Dullerud, R. \& Haakonsen, M. 2000 Unawareness of illness in chronic schizophrenia and its relationship to structural brain measures and neuropsychological tests. Psychiat. Res. 100, 49-58. (doi:10.1016/S0925-4927(00)00063-9)

84 Flashman, L. A., McAllister, T. W., Johnson, S. C., Rick, J. H., Green, R. L. \& Saykin, A. J. 2001 Specific frontal lobe subregions correlated with unawareness of illness in schizophrenia: a preliminary study. 7. Neuropsychiatr. Clin. Neurosci. 13, 255-257. (doi:10. 1176/appi.neuropsych.13.2.255)

85 Sapara, A. et al. 2007 Prefrontal cortex and insight in schizophrenia: a volumetric MRI study. Schizophr. Res. 89, 22-34. (doi:10.1016/j.schres.2006.09.016)

86 Shad, M. U., Muddasani, S. \& Keshavan, M. S. 2006 Prefrontal subregions and dimensions of insight in firstepisode schizophrenia - a pilot study. Psychiat. Res. 146, 35-42. (doi:10.1016/j.pscychresns.2005.11.001)

87 Ha, T., Youn, T., Ha, K., Rho, K., Lee, J., Kim, I., Kim, S. \& Kwon, J. 2004 Grey matter abnormalities in paranoid schizophrenia and their clinical correlations. Psychiat. Res. Neuroimag. 132, 251-260. (doi:10.1016/ j.pscychresns.2004.05.001)

88 Cooke, M.A., Fannon, D., Kuipers, E., Peters, E., Williams, S.C. \& Kumari, V. 2008 Neurological basis of poor insight in psychosis: a voxel-based MRI study. Schizophr. Res. 103, 40-51. (doi:10.1016/j.schres. 2008.04.022)

89 Bassitt, D. P., Neto, M. R. L., de Castro, C. C. \& Busatto, G. F. 2007 Insight and regional brain volumes in schizophrenia. Eur. Arch. Psychiat. Clin. Neurosci. 257, 58-62. (doi:10.1007/s00406-006-0685-z)

90 Antonius, D., Prudent, V., Rebani, Y., D’Angelo, D., Ardekani, B.A., Malaspina, D. \& Hoptman, M.J. 2011 White matter integrity and lack of insight in schizophrenia and schizoaffective disorder. Schizophr. Res. 128, 76-82. (doi:10.1016/j.schres.2011.02.020)

91 Berge, D., Carmona, S., Rovira, M., Bulbena, A., Salgado, P. \& Vilarroya, O. 2010 Gray matter volume deficits and correlation with insight and negative symptoms in first-psychotic-episode subjects. Acta. Psychiatr. Scand. 123, 1-9. (doi:10.1111/j.1600-0447.2010. 01635.x)

92 Buchy, L., Ad-Dab'bagh, Y., Malla, A., Lepage, C., Bodnar, M., Joober, R., Sergerie, K., Evans, A. \& Lepage, M. 2010 Cortical thickness is associated with poor insight in first-episode psychosis. F. Psychiat. Res. 45, 781-787. (doi:10.1016/j.jpsychires. 2010.10.016)

93 Morgan, K. D. et al. 2010 Insight, grey matter and cognitive function in first-onset psychosis. Brit. F. Psychiat. 197, 141-148. (doi:10.1192/bjp.bp.109.070888)

94 Schmitz, T. W. \& Johnson, S. C. 2007 Relevance to self: a brief review and framework of neural systems underlying appraisal. Neurosci. Biobehav. Rev. 31, 585-596. (doi:10.1016/j.neubiorev.2006.12.003)

95 Northoff, G., Heinzel, A., de Greck, M., Bermpohl, F., Dobrowolny, H. \& Panksepp, J. 2006 Self-referential processing in our brain-a meta-analysis of imaging studies on the self. Neuroimage 31, 440-457. (doi:10. 1016/j.neuroimage.2005.12.002)

96 Berti, A., Bottini, G., Gandola, M., Pia, L., Smania, N., Stracciari, A., Castiglioni, I., Vallar, G. \& Paulesu, E. 2005 Shared cortical anatomy for motor awareness and motor control. Science 309, 488-491. (doi:10. 1126/science.1110625)

97 Fleming, S. M., Weil, R. S., Nagy, Z., Dolan, R. J. \& Rees, G. 2010 Relating introspective accuracy to individual differences in brain structure. Science 329, 1541-1543. (doi:10.1126/science.1191883)

98 van der Meer, L., Costafreda, S. C., Aleman, A. \& David, A. S. 2010 Self-reflection and the brain: a theoretical review and meta-analysis of neuroimaging studies with implications for schizophrenia. Neurosci. Biobehav. Rev. 34, 935-46. (doi:10.1016/j.neubiorev.2009.12.004)

99 David, A. S., Bedford, N., Gilleen, J., Greenwood, K., Morgan, K. \& Wiffen, B. 2001 The etiology of lack of insight in schizophrenia. Schizophr. Bull. 37(suppl 1), 14.

100 Holt, D. J., Cassidy, B. S., Andrews-Hanna, J. R., Lee, S. M., Coombs, G., Goff, D. C., Gabrieli, J. D. \& Moran, J. M. 2011 An anterior-to-posterior shift in midline cortical activity in schizophrenia during selfreflection. Biol. Psychiat. 69, 415-423. (doi:10.1016/j. biopsych.2010.10.003)

101 Modinos, G., Renken, R., Ormel, J. \& Aleman, A. 2011 Self-reflection and the psychosis-prone brain: an fMRI study. Neuropsychology 25, 295-305. (doi:10.1037/ a0021747)

102 Nelson, T. O. \& Narens, L. 1990 Metamemory: a theoretical framework and some new findings. In The psychology of learning and motivation, vol. 26 (ed. G. H. Bower), pp. 125-173. San Diego, CA: Academic Press. 